\title{
ANALYSIS OF THE VIBRATION PROPAGATION IN THE SUBSOIL
}

\author{
MAŁGORZATA JASTRZĘBSKA, MARIAN ŁUPIEŻOWIEC, \\ RAFAE ULINIARZ, ARTUR JAROŃ \\ Silesian University of Technology, Faculty of Civil Engineering, Gliwice, Poland, \\ e-mail: malgorzata.jastrzebska@polsl.pl, marian.lupiezowiec@polsl.pl, \\ rafal.uliniarz@polsl.pl, artur.jaron@gmail.com
}

\begin{abstract}
The paper presents in a comprehensive way issues related to propagation in a soil environment of vibrations originating during sheet piling vibratory driving. Considerations carried out comprised the FEM analysis of initial-boundary behaviour of the subsoil during impacts accompanying the works performed. The analysis has used the authors' RU+MCC constitutive model, which can realistically describe complex deformation characteristics in soils in the field of small strains, which accompany the phenomenon of shock propagation. The basis for model creation and for specification of material parameters of the presented model consisted of first-class tests performed in a triaxial apparatus using proximity detectors guaranteeing a proper measurement of strains ranging from $10^{-1}$ to $10^{-3} \%$ and bender elements. Results obtained from numerical analyses were confronted with results of field tests consisting in measurements of acceleration amplitudes generated on the ground surface due to technological impacts versus the distance from vibration source.
\end{abstract}

Key words: soil characteristics in small strain range, triaxial tests, dynamic analysis

\section{INTRODUCTION}

Most technologies used in soil engineering utilise impacts or shocks to strengthen the subsoil or to introduce structural elements to the soil, supporting foundations or slopes. The same situation occurs in the case of sheet piling made from steel piles. Vibratory driving is one of the methods of driving them into the subsoil, which causes origination of vibrations having an adverse impact on the environment. Proper recognition of phenomena occurring in the subsoil during propagation of waves and a possibility of effective prediction of their adverse impact range is crucial in designing and executing construction works.

In practical cases accelerations (vertical and horizontal) typically are measured on the surface of structural elements. The measured amplitudes are compared with the values in the standard, which allows impacts to be classified to the specific risk groups of damaging the structure. In the literature there are no many studies about the phenomenon of wave propagation in the subsoil. More common is the problem of seismic impact, as a result of the deep geological process. Influence on structures in the case of relatively shallow vibration sources, like the sheet piling process discussed, is still not solved.

This paper makes an attempt at comprehensive description of the phenomenon of vibrations, originating during steel piles driving into the subsoil, propagation in a soil environment. The soil properties recognition based on first-class laboratory tests is the basis for modelling its behaviour under dynamic influences. In this case, description of a complex deformation characteristic of the soil, within the range of small strains (ranging from $10^{-1}$ to $10^{-3} \%$ ), usually accompanying the shock propagation is crucial. Recognition of these properties requires a triaxial apparatus equipped with local measurement of tested soil sample deformations and bender elements. The next stage of the analysis consists in building a constitutive model, which will be capable of describing properly the phenomena discussed in the paper. The possibility to specify model parameter values based on laboratory or field tests is extremely important. Preparation of appropriate procedures using backward analysis methods is helpful. The created constitutive model is the basis to resolve the initial-boundary issue describing the problem of vibrations propagation in a soil environment. This is possible after the implementation of proposed model 
into the structure of available Finite Element Method software. Having a tool prepared in this way, it is possible to perform analyses modelling the phenomenon discussed. Obtainment of realistic calculation results is conditioned by using appropriate model parameter values. To this end it is necessary to perform proper laboratory tests and - first of all - field tests, used for the subsoil recognition. Unfortunately, in the case of majority of investments implemented in Poland traditional geological surveys prevail, consisting only in recognition of the type and condition of soil existing in the subsoil, while there are no estimations of necessary parameters (stiffness and damping) for complex analysis of the soil behaviour. Such situation to a large extent hinders estimation of parameters of the model adopted in analyses and causes a necessity to rely on results of laboratory tests of similar soil types and on the data available in the literature.

A complete process of modelling such phenomena should consist in creation of the model and its field verification. The first one contains specification of the model equations, which simulate soil behaviour under loading including specific effects (for instance, dynamic ones). Very important are the parameters of the model created, which values should be specified by precision laboratory tests. Finally, calculation results should be verified in field test, based on the measurement of accelerations of soil surface or structure elements. The following paper shows an example of using full above mentioned paths of modelling the title problem.

\section{FIELD TESTS}

In March 2012, field tests were carried out in the south-east part of Cracow city (Podgórze district), consisting in measuring vibrations propagating in the subsoil, caused by driving steel piling by means of a vibratory pile driver. Geotechnical conditions on site of measurements carried out were recognised and described in the geotechnical documentation, prepared in January 2011 by a local geological company, and also based on sounding using a light driving rod performed in April 2012 (Documentation [16], [17]). The most important information related to the subsoil structure is specified below. In addition, the nature of the works carried out was described in detail, i.e., the specification of sheet piles driving and of the measuring equipment as well as the measurement procedure (Jaroń [5]).

\subsection{GEOTECHNICAL CONDITIONS}

Parameters of all layers were chosen based on geoengineering documentation.

The first layer is a $1.5 \mathrm{~m}$ thick sandy clay featuring liquidity index $I_{L}=0.35$. Layer II is a $2.0 \mathrm{~m}$ thick silty clay featuring liquidity index $I_{L}=0.35$. The next layers are made of clays featuring liquidity indices $0.12,0.40$ and $0.05 ; 1 \mathrm{~m}, 1 \mathrm{~m}$ and $10 \mathrm{~m}$ thick, marked as layers III, IV and V, respectively. Geotechnical profiles together with selected geotech-

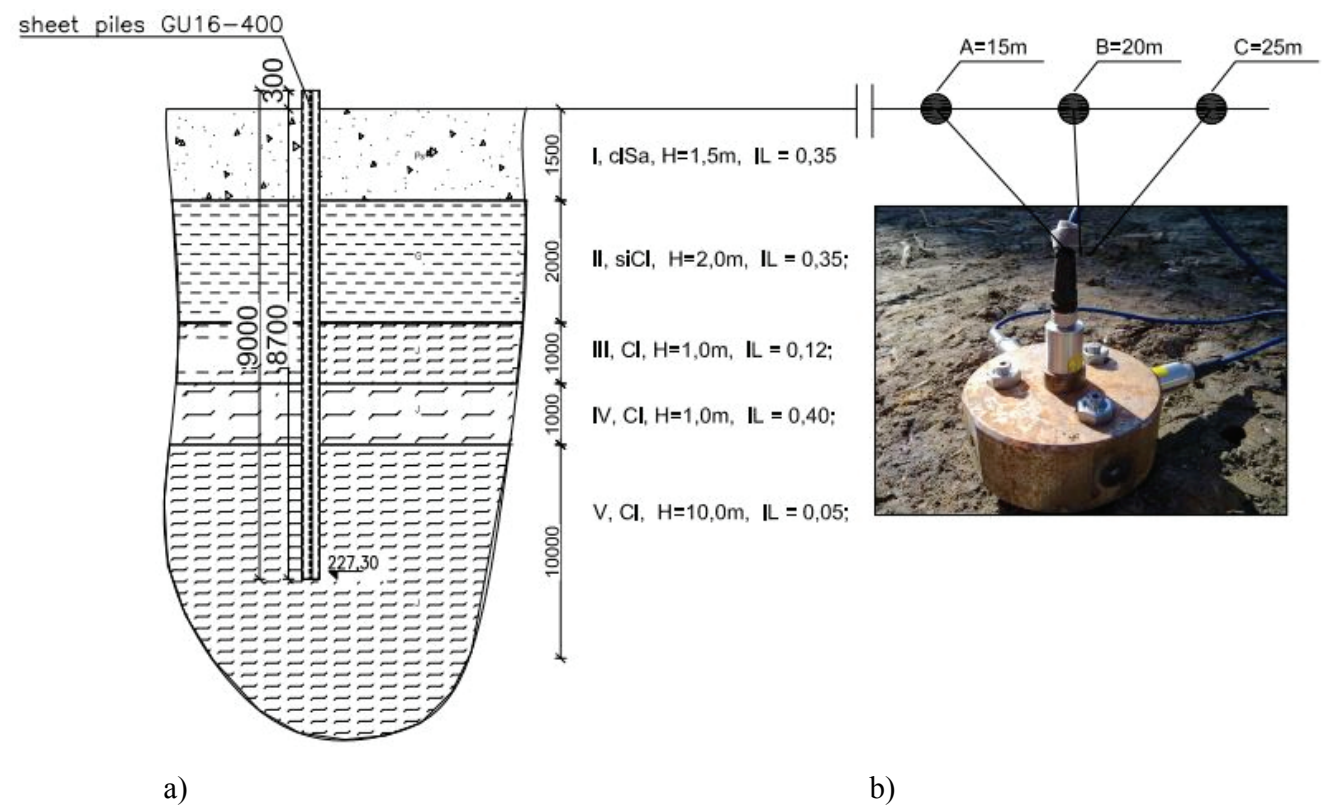

Fig. 1. General view of field tests site: (a) geotechnical profile with selected soil parameters, (b) picture of the stand and of vibration sensors situated at a distance of 15, 20 and $25 \mathrm{~m}$ from the place of sheet piles driving 
nical parameters are schematically presented in Fig. 1a.

\subsection{SHEET PILES VIBRATORY DRIVING}

Steel sheet piles are prefabricated elements, which are applied mainly as a temporary or permanent protection of deep excavations against the groundwater inflow and/or to protect excavation walls.

Measurements were carried out during engineering works consisting in protection of a deep excavation. GU16-400 steel piles were used for that, each $9 \mathrm{~m}$ long and $558 \mathrm{~kg}$ in total weight, the geometrical and strength characteristic of which is presented in Fig. 2. It is an extremely popular type of piles in Poland, because in the past it was manufactured by Polish steelworks and then was marked G62 (based on its weight $-62 \mathrm{~kg} / \mathrm{m}$ ). These sheet piles have poor strength parameters as against their weight as compared to other $\mathrm{U}$ type sheet piles, but are tougher dur- ing vibratory driving and better fit for multiple use, that is, temporary protection of cuts.

Sheet piles were driven using a Bauer MR100V-2 vibratory pile driver of high vibration frequency equal to $40 \mathrm{~Hz}$ and of maximum $9 \mathrm{~mm}$ amplitude. A vibration pile driver works on a large-size crawler machine, approx. $60 \mathrm{t}$ in weight. Vibration pile driver characteristic and a picture of the whole machine are presented in Fig. 3.

\subsection{MEASURING EQUIPMENT}

Tests were aimed at carrying out measurements of acceleration (horizontal and vertical) on the ground surface, where the maximum values of vibration parameters occur (Ciesielski et al. [1]).

Sensor CAL100 accelerometers of $1.0 \mathrm{~V} / \mathrm{g}$ sensitivity, measuring range of $0-10 \mathrm{~m} / \mathrm{s}^{2}$ and frequency range $>0.5 \mathrm{~Hz}$ were used to perform the task. Measurements were performed using a 16-channel KSD-400 diagnostic spectrum analyser. Data from 9 accelerometers

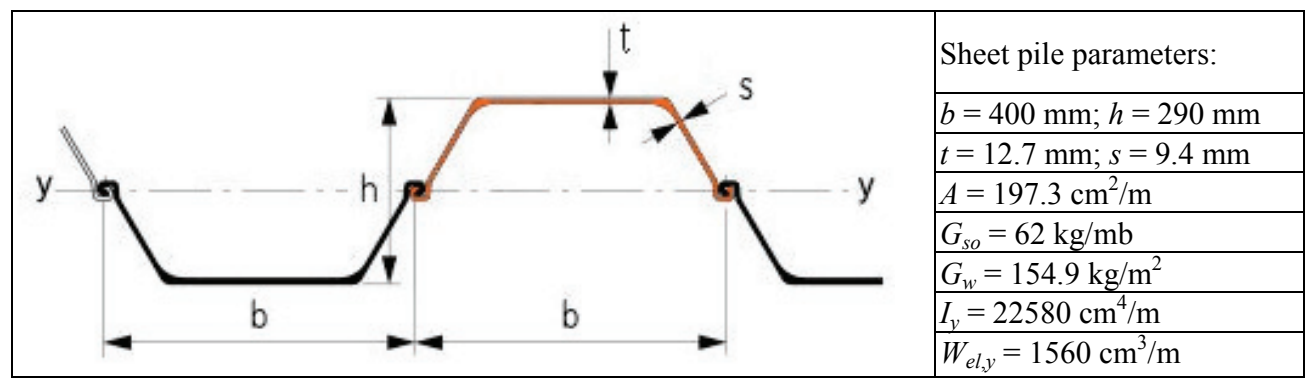

Fig. 2. Sheet pile parameters: $A$ - area, $G_{s o}$ - weight of $1 \mathrm{~m}$ of pile, $G_{w}-$ weight of $1 \mathrm{~m}^{2}$ of pile, $I_{y}$ - moment of inertia, $W_{\text {el. } y}$ - elastic bending coefficient

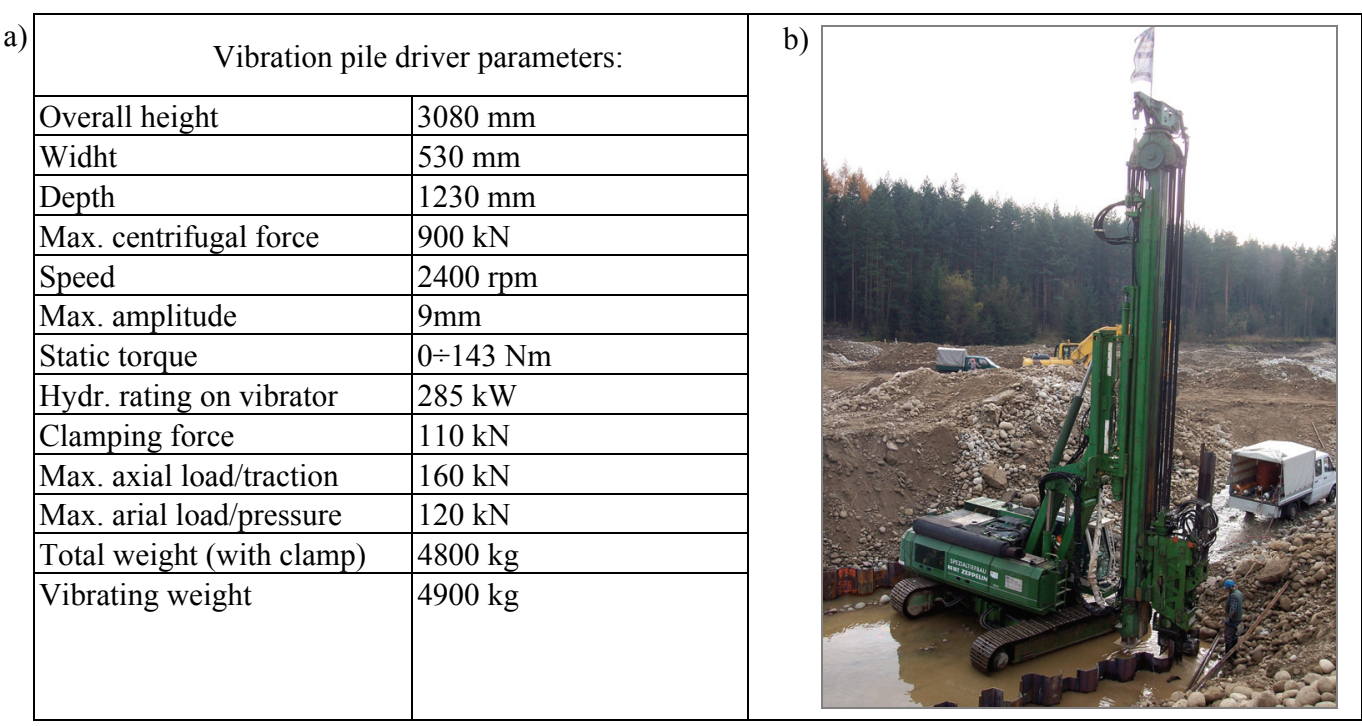

Fig. 3. RTG type machine during pile vibratory driving: (a) parameters of Bauer MR100V-02 vibration pile driver, (b) general machine view during operation 


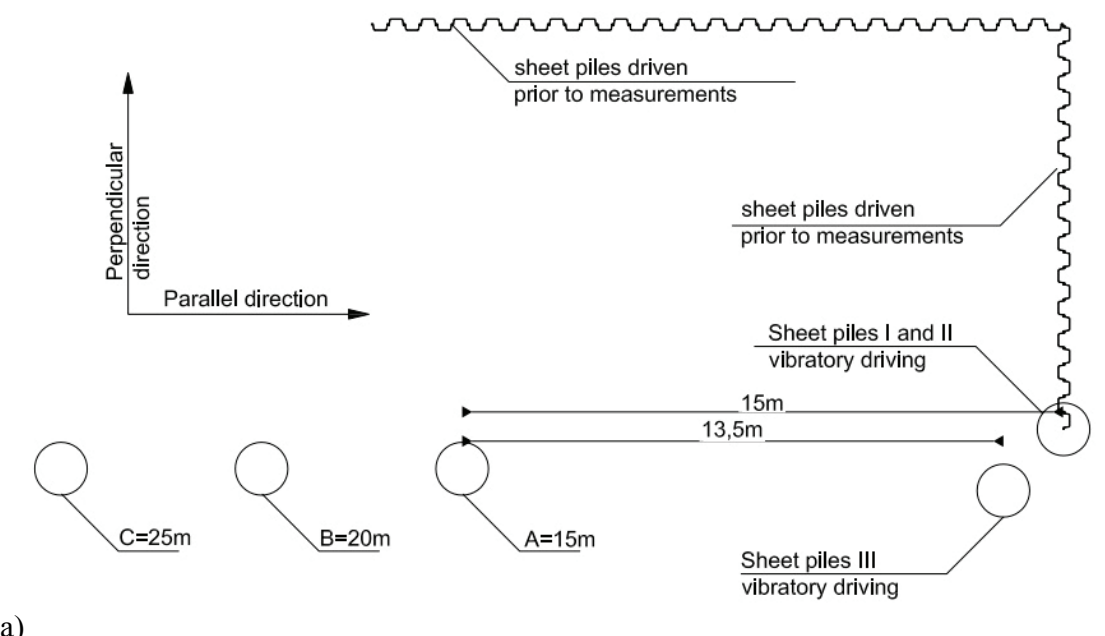

b)

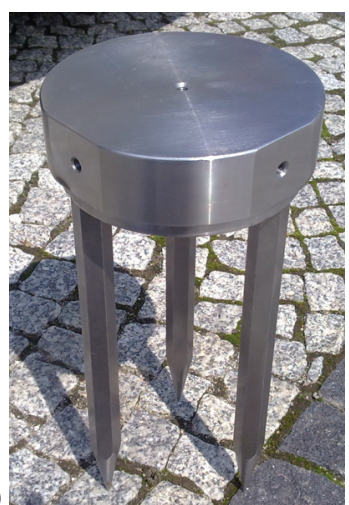

Fig. 4. Location plan of measurements performed (a) and a view of the stand (b)

were parallel registered during measurements. They were situated at three measurement points at a distance of 15 (A), 20 (B) and 25 (C) metres from the place of sheet pile vibratory driving. Effective values of RMS (root mean square) acceleration in a vertical and in two horizontal directions were measured at each of these points, i.e., perpendicular and parallel to the measurement profile, which is presented in Fig. $1 \mathrm{~b}$ and 4a. Figure $4 \mathrm{~b}$ presents also a measuring stand prototype (prior to driving into the ground and mounting of accelerometers), consisting of a steel cylinder and 3 steel rods of circular cross-section. Rods and the cylinder are bolted together. The whole stand is $13.5 \mathrm{~kg}$ in weight. The cylinder has threaded holes, visible in Fig. 4b, where accelerometers are placed.

Values of instantaneous samples of vibration accelerations and the measured signal spectrum were observed during measurements.

\subsection{COURSE OF MEASUREMENT WORK}

Three types of resistance occur during sheet pile vibratory driving: soil resistance under the pile base, resistance on the side surface and sheet pile friction in the lock. The excavation protection designer assumed vibratory driving of sheet piles $9 \mathrm{~m}$ long, hence reaching by their bases to the layer of semicompact clays, and sunk in them along a section of approx. $4 \mathrm{~m}$. However, the nature of this soil layer requires to carry out piles driving with pressurised water jetting.

This method consists in supplying a controlled amount of water under pressure to the sheet pile base through a pipe, small in diameter, welded to the sheet pile (Jarominiak [4]).
The difficulty of this technology consists in optimal choosing the discharge and pressure of water. It is assumed that the pressure should be high enough to destroy the soil structure just under the sheet pile and also to cause water return to the surface, while the amount of water small enough not to overly deteriorate the soil mechanical properties, especially below the excavation level. This way the soil resistance is partially reduced under the sheet pile base and on its side surface, where the returning water causes the effect of lubrication, minimizing the soil friction against the sheet pile surface (Zeilinger [14]). Apart from the fed water volume and its pressure, also the number of pipes is important, the way of their ending, diameter of the nozzles and their direction, hence generally the shape of jetted sheet pile head.

Measurements were carried out during vibratory driving of three GU16-400 sheet piles, each $9 \mathrm{~m}$ long. The first of them (I) was impact driven using pressurised water jetting. A single pipe was fixed to the sheet pile, enabling feeding pressurised water at the sheet pile base. The pump working pressure was $51.5 \mathrm{MPa}$ and the maximum water discharge was reaching $51 \mathrm{dm}^{3} / \mathrm{min}$. Sheet pile I was impact driven without putting it on the adjacent pile lock, i.e., it was not threaded, and then was pulled out from the subsoil.

The second sheet pile (II) was impact driven without jetting, but in the place where sheet pile I was previously driven. Previous jetted sheet pile driving was to facilitate sheet pile vibratory driving without jetting in the same place, which is feasible only in cohesive soils. In this way a sheet pile prepared for jetting may be used many times. Sheet pile II was part of ultimate excavation protection and was threaded on the lock of sheet piles driven on the previous day. Sheet pile threading on the lock during vibratory 
driving causes origination of additional resistances, increasing the value of vibrations in the subsoil (Legrand et al. [8]; Viking [13]). It is difficult to determine how large is the participation in measured acceleration of sources like sheet driving and resistance on the lock. It will be the subject of further studies. Because of that results of vibration measurement for sheet pile II will not be considered in the present paper.

The third sheet pile (III) was impact driven without jetting and around $1.5 \mathrm{~m}$ closer to vibration sensors than the previous two sheet piles. This shift away was aimed at neglecting in vibration measurements the influence of soil previously modified by feeding a pressurised water. This sheet pile was not threaded.

Tests were carried out in a construction site conditions.

Summing up, measurements were made for three sheet piles: using jetting and without threading (sheet pile I); with threading in the place where previously a sheet piles was impact driven with jetting (sheet pile II - results not considered in this paper) and without jetting and threading (sheet pile III). Sheet piles were driven using a vibration pile driver of $40 \mathrm{~Hz}$ vibration frequency and $9 \mathrm{~mm}$ maximum amplitude. The measurements of vibration parameters were performed at 3 points $(\mathrm{A}, \mathrm{B}, \mathrm{C})$ and in 3 directions at each of the points, i.e., altogether parallel in 9 channels. The subsoil consisted mainly of cohesive soils. Measurements were carried out during the daytime, around noon, in a dry weather and at a temperature of around $10^{\circ} \mathrm{C}$.

\section{LABORATORY TESTS}

The knowledge of stiffness changes of soils building the subsoil, being the subject of measurements, is necessary for the needs of the present paper. Unfortunately, the authors did not have a possibility of performing necessary deformation tests on samples taken from the site. Therefore, a correlation was applied between real soils and parameters of soils of similar physical structure and existing in the database of the Department of Geotechnics of the Silesian University of Technology and collected based on results of the authors' own research and research carried out in cooperation with the Warsaw University of Live Sciences (SGGW) in Warsaw (Jastrzębska [6], [7]; Lipiński et al. [9]).

\subsection{TEST STAND AND TESTING PROCEDURE}

All tests were carried out in a conventional triaxial apparatus. A modified apparatus chamber (Fig. 5a) contains internal linking rods and a stiff joint between the dome and the piston rod. Perimeter drainage of a filter paper was applied as well as porous stones built-in in the triaxial apparatus base and dome. The pressure chamber was filled with deaerated water. Local measurement of soil sample strains $\left(\varepsilon_{1}\right.$ and $\left.\varepsilon_{3}\right)$ was performed using six contactless Kaman microdisplacement sensors of measuring range and resolution equal to $2.0 \mathrm{~mm}$ and $0.01 \%$, respectively. Their arrangement is presented in Fig. $5 \mathrm{~b}$ and $5 \mathrm{c}$. Additionally, an external measurement $\left(\varepsilon_{1}\right)$ was made using a sensor placed on the piston.

Moreover, the testing stand at the SGGW is equipped with a measuring set enabling transmission of acoustic waves through specimens. This set consists of: generator of electric signals, selective amplifier, digital oscilloscope and piezoelectric transducers built-in in the base (transmitter) and in the dome (receiver) of a modified triaxial apparatus; electrical cables leading outside the chamber are connected to those electrodes (Fig. 6).

All tests were carried out on samples $50 \mathrm{~mm}$ in diameter and $100 \mathrm{~mm}$ high. Because of samples satura-
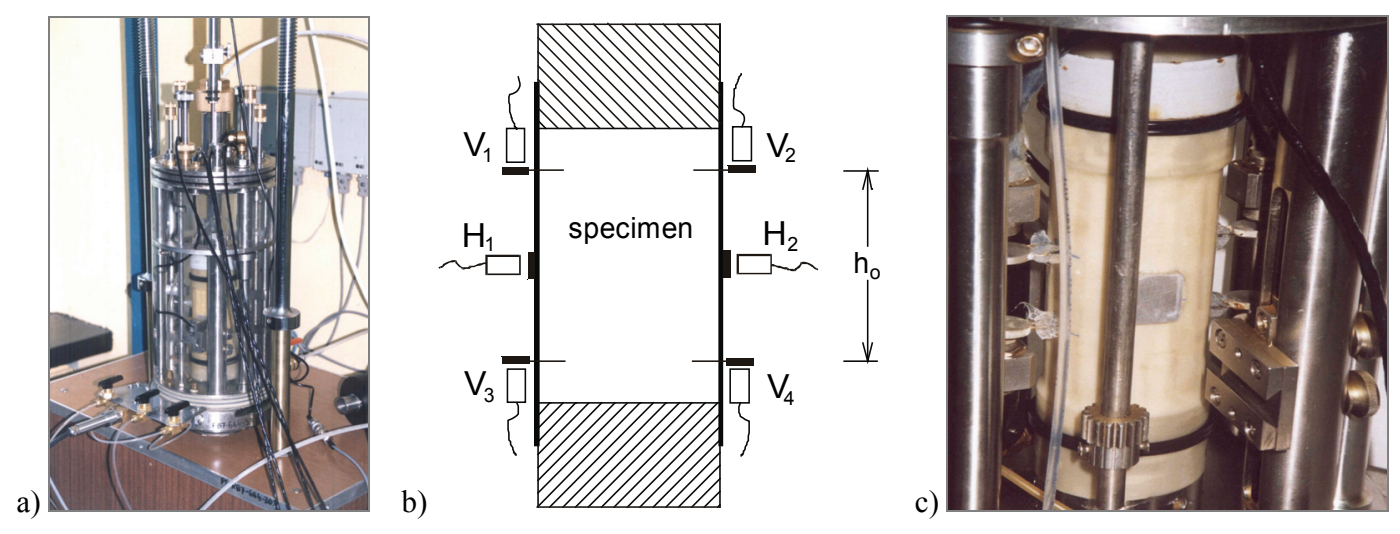

Fig. 5. Test stand: (a) modified chamber of the triaxial apparatus in the Department of Geotechnics, Silesian University of Technology; (b) basic configuration of six sensors system for micro-strains measurements, (c) specimen with six local sensors mounted 
tion using the "back pressure" method the obtained Skempton B parameter value was higher than 0.95.

\subsection{RESULTS OF TESTS}

Results of the Warsaw area soil tests, presented in Fig. 7 (Lipiński et al. [9]), have been used for the needs of this paper. Figure 7a shows values of initial shear modulus $G_{0}$ compared for cohesive soils of plasticity index $I_{p}>30 \%$, while Fig. $7 \mathrm{~b}$ for $I_{p}<30 \%$. It is clearly visible that the less cohesive soils $\left(I_{p}<\right.$ $30 \%$ ) are more sensitive to stress changes (there is higher trend line inclination for more cohesive soils with $I_{p}>30 \%$ ), which caused higher variability of the initial shear modulus $\mathrm{G}_{0}$. In the group of more cohesive soils $\left(I_{p}>30 \%\right)$ the variability of the modulus is lower and similar for each of the samples. Such behaviour may be explained by the fact that issue group

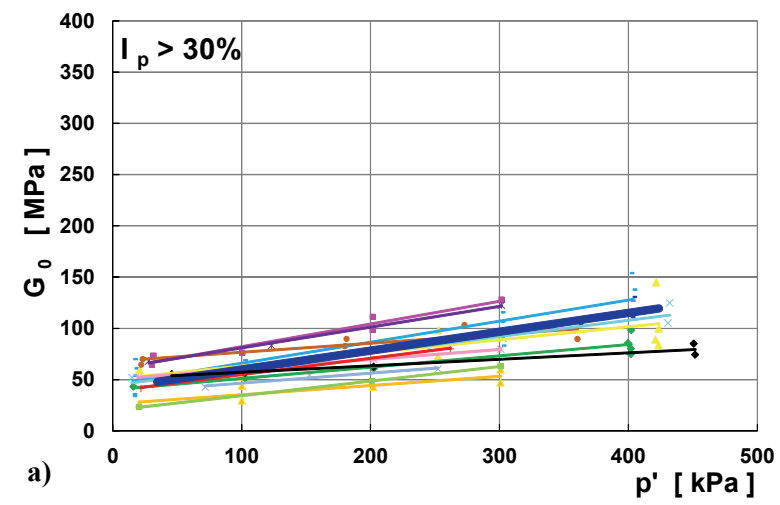

\section{RU+MCC MODEL}

For further calculations a new small strain critical state model has been used. The RU+MCC model (Gryczmański and Uliniarz [2]; Uliniarz [12]) is one of the new concepts which have been developed especially in order to describe realistically, and as simply as possible, the stress-strain strong nonlinearity in small strain zone (Fig. 8). The RU part is a hypoelastic model and a development on the known Jardine's proposal (Jardine et al. [3]) inside the yield locus. The RU does not explicitly take into account plastic deformations and the limit state. Using this model part alone for a correct simulation of soil behaviour within the whole range of loads, up to the bearing capacity, is therefore impossible, or at least questionable.

This justifies the idea of combining both constitutive laws. The RU model part is assumed to be

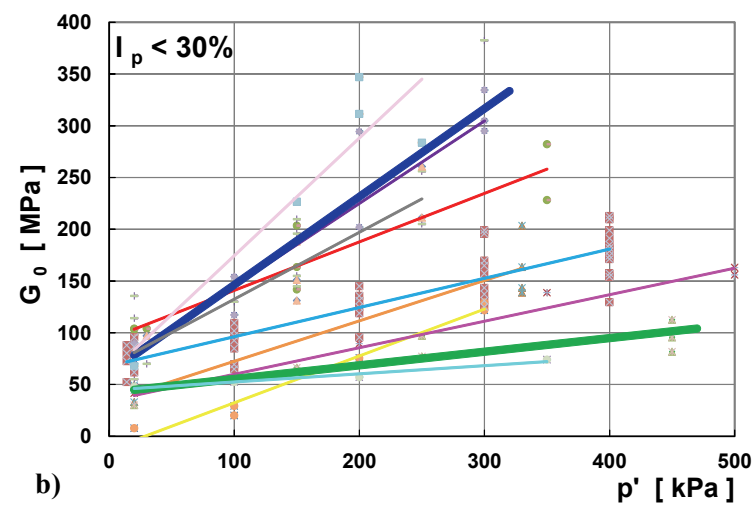

Fig. 7. Shear modulus versus average effective stress in soils under study:

(a) for $I_{p}>30 \%$, (b) $I_{p}<30 \%$ (Lipiński et al. [9])

of soils with $I_{p}>30 \%$ is too wide and includes various soil types (opposite to homogeneous group of soils with $I_{p}>30 \%$, for which the high contents of clay fraction is characteristic). Finally, taking into account soils making up the subsoil considered, their depth of occurrence and corresponding average effective stress $p^{\prime}$, averaged $G_{0}$ values for $p^{\prime}=25 \div 100 \mathrm{kPa}$ were taken for numerical analyses. The following values of the shear modulus $G_{0}$ correspond to that:

$$
\begin{aligned}
I_{p}>30 \% \text { and } I_{L} & \in(-0.2 ; 0.009): \\
p^{\prime}=25 \mathrm{kPa} & \rightarrow G_{0} \in(15 \mathrm{MPa}, \quad 65 \mathrm{MPa}), \\
p^{\prime}=100 \mathrm{kPa} & \rightarrow G_{0} \in(25 \mathrm{MPa}, \quad 75 \mathrm{MPa}), \\
I_{p}<30 \% \text { and } I_{L} & \in(-0.07 ; 0.45): \\
p^{\prime}=25 \mathrm{kPa} & \rightarrow G_{0} \in(5 \mathrm{MPa}, 120 \mathrm{MPa}), \\
p^{\prime}=100 \mathrm{kPa} & \rightarrow G_{0} \in(30 \mathrm{MPa}, \quad 175 \mathrm{MPa}) .
\end{aligned}
$$

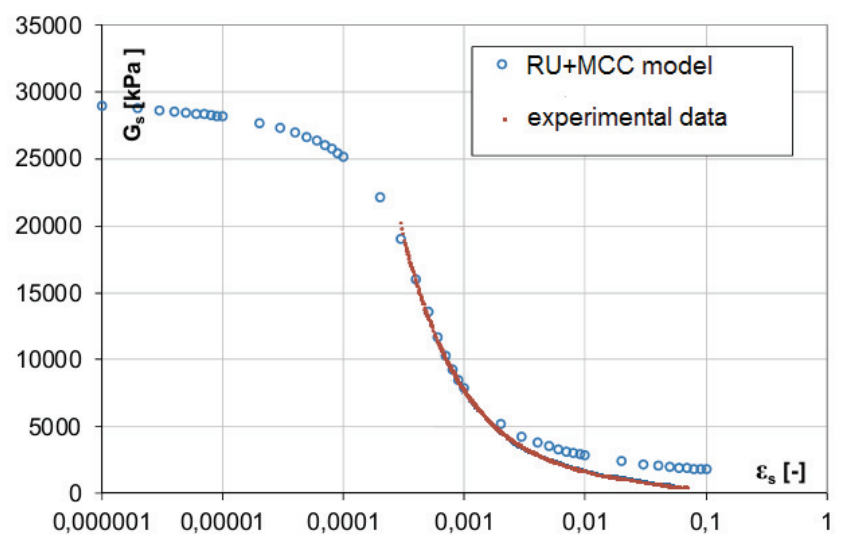

Fig. 8. Typical RU+MCC relationship of " $G-\varepsilon_{S}$ " vs. experimental triaxial test data

valid within the overconsolidation area, i.e. in the stress subspace confined by the current configuration of MCC yield locus. For normal consolidation states, 
occurring in the remaining physically admissible stress subspace, mechanical soil behaviour is described by the Modified Cam Clay. Continuous transition from one model to the other is achieved through treating the bulk and shear moduli as the same parameters for both models, though differently defined within each of the above mentioned stress subspaces.

The hybrid constitutive model for soil developed in this paper differs from the Modified Cam Clay only in "stress-strain" relations inside the state boundary surface in the stress space which encloses a subspace of real physical states of material. Since the RU model has been conceived as a hypoelastic one, the above difference does extend to the nature of deformation. For both cases strains are assumed to be entirely reversible. In fact, the above divergence only concerns the forms of tangent shear, bulk and Young's elastic moduli as stress path dependent. While for the Modified Cam Clay these are simple linear functions of the effective mean stress, for Uliniarz [12] concept, and thereby for the combined model inside the state boundary surface, the elastic moduli are to describe adequately the above mentioned phenomenon of strong small strain nonlinearity. For this purpose some complex hyperbolic functions of the stress intensity are required beside of simple dependence on the effective mean stress.

The key characteristic of the model proposed is equation (1) of the state boundary surface

$$
F=q^{2}+M^{2} p^{\prime}\left(p^{\prime}-p_{c}^{\prime}\right)=0,
$$

which at the same time is the yield locus for $M C C$.

In equation (1), $p^{\prime}$ is the effective mean stress, $q$ - the stress intensity, $p_{c}^{\prime}-$ the preconsolidation pressure, and $M$ - the slope of the critical state line (CSL) in the $p^{\prime}-q$ space.

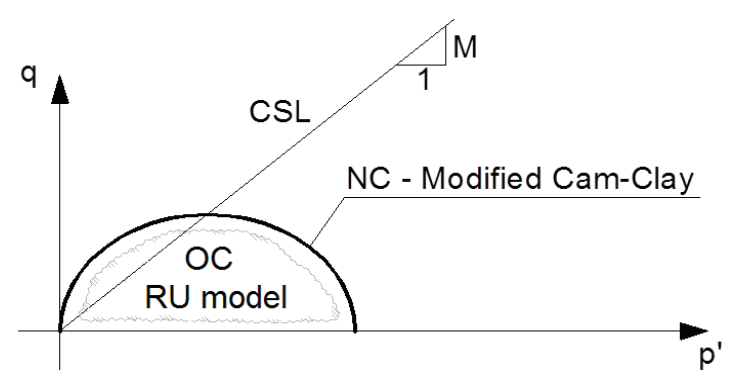

Fig. 9. Graphic representation of the combined FC+MCC model in the " $p$ ' $q$ " space

Identification of the state boundary (MCC yield) surface enables illustration of the division of the physically admissible subspace into the subregions of validity of the component models (Fig. 9). It is necessary to remember that external subregion in which the MCC is valid evolves together with irreversible changes of void ratio. This state boundary locus expands when soil undergoes densification, and contracts upon soil loosening.

The above state boundary surface evolutions are governed by the law (2) of isotropic hardening dependent on the irreversible changes of void ratio (or volumetric strain)

$$
p_{c}^{\prime}=p_{c 0}^{\prime} \exp \left(\frac{\Delta e^{p}}{\lambda-\kappa}\right)
$$

where $p_{c 0}^{\prime}$ is an initial value of the preconsolidation pressure, $\Delta e^{p}$ - the total irreversible change of void ratio, $\lambda$ and $\kappa$-slopes of the normal consolidation and swelling lines in semi-logarithmic scales.

The tangent elastic bulk modulus is given by equation (3)

$$
K_{t}=\frac{\left(1+e_{0}\right) p^{\prime}}{\kappa},
$$

whereas the tangent elastic shear modulus by equation (4)

$$
G_{t}=\frac{3(1-2 v)}{2(1+v)} K_{t}
$$

where $v$ is Poisson's ratio assumed to be constant Formulas (3) and (4) are valid on the state boundary surface, where they describe the elastic part of deformation. The combined soil model turns there into Modified Cam Clay.

Inside SBS the hybrid model becomes the RU hypoelastic one. Its original version is defined by the tangent elastic shear modulus expressed as follows by equations (5) and (6)

$$
G_{t}=\left\{G_{0} \frac{-1}{\pi} \frac{t_{1}}{t_{2}} \frac{1}{\varepsilon_{S} \ln 10}\left[1+\left(\frac{t_{1}}{t_{2}}\left(\log \left(\varepsilon_{S}\right)+6\right)-t_{1}\right)^{2}\right]^{-1}\right\}
$$

where $G_{0}$ - initial shear modulus, $\varepsilon_{S}$ - shear strain, $t_{1}, t_{2}$ - material constants.

$$
G_{0}=G^{*}\left(\frac{p^{\prime}}{p_{a}}\right)^{n}
$$

where $G^{*}, n$ - material constants, $p_{a}$ - reference pressure $1 \mathrm{kPa}$.

The tangent elastic bulk modulus is given by equation (7) 


$$
K_{t}=\frac{2(1+v)}{3(1-2 v)} G_{t} .
$$

Initial shear modulus $G_{0}$ in the RU+MCC model is defined in a simple way as a function of the effective mean stress $p^{\prime}$ (6). Two constants $G^{*}$ and $n$ complement, with $t_{1}, t_{2}$ and a standard MCC's, a full set of the model parameters.

\section{NUMERICAL ANALYSIS}

Analyses comprised a numerical resolution of the issue of shocks propagation, generated by vibratory driving of sheet piling into the subsoil. The Finite Element Method was used for the solution and computations were carried out using software Z-Soil_ver. 2011. The analysed initial-boundary issue is presented in Fig. 10. A solution of differential equation of motion (8) was sought in calculations

$$
\mathbf{M} \cdot \ddot{\mathbf{u}}+\mathbf{C} \cdot \dot{\mathbf{u}}+\mathbf{K} \cdot \mathbf{u}=\mathbf{P}(t) .
$$

In the above relationship, $\mathbf{u}(\mathbf{x}, t)$ is the sought field of displacements at any moment of time $t$, while values $\mathbf{M}, \mathbf{C}$ and $\mathbf{K}$ are matrices of inertia, damping and stiffness, respectively. Vector $\mathbf{P}(t)$ is a force, which in the case discussed is caused by shock origination at the moment of sheet pile vibratory driving. This force amplitude is $900 \mathrm{kN}$ and its frequency - assuming a harmonic course - is $40 \mathrm{~Hz}$. It is extremely important to assign an appropriate dumping mechanism, which has a decisive influence on vibrations decay in the subsoil, which directly affects the range of shocks impact on the neighbourhood. In numerous dynamic analyses this damping may be assumed in the form of (9) suggested by Rayleigh (Zimmermann et al. [15]):

$$
\mathbf{C}=\alpha \cdot \mathbf{M}+\beta \cdot \mathbf{K} .
$$

In the above relationship, constants $\alpha$ and $\beta$ are damping parameters. The influence of these parameter values on the obtained results of analyses may be found in the paper by Łupieżowiec [10], where attention was paid to a relatively high ease in the damping model calibration based on available field tests. In further analyses an assumption was made that $\alpha=1.0 \mathrm{~s}^{-1}$ and $\beta=0.03 \mathrm{~s}$. In the presented issue damping will affect the value of acceleration amplitudes observed versus the distance from the force source.

In the analyses performed an assumption was made that the subsoil recognised based on simple geotechnical tests is described by the material model described in detail in Section 4. This model has been implemented in the Z_Soil software as an additional user model and its task is to consider a complex stress-strain characteristics in the field of soil environment response within the range of strains occurring during the wave propagation. Values of parameter $G^{*}$ (see equation (6), where a relation of $p^{\prime}$ with mean stress in responding layers is shown), which accounts for the environment stiffness for strains ranging from $10^{-1}$ to $10^{-3} \%$, are presented in Table 1 . Values of model parameters were estimated based on trends obtained from first-class triaxial tests described in Section 3. For clays (layers III, IV, V) the relationships shown in Fig. 7a were used, while for the

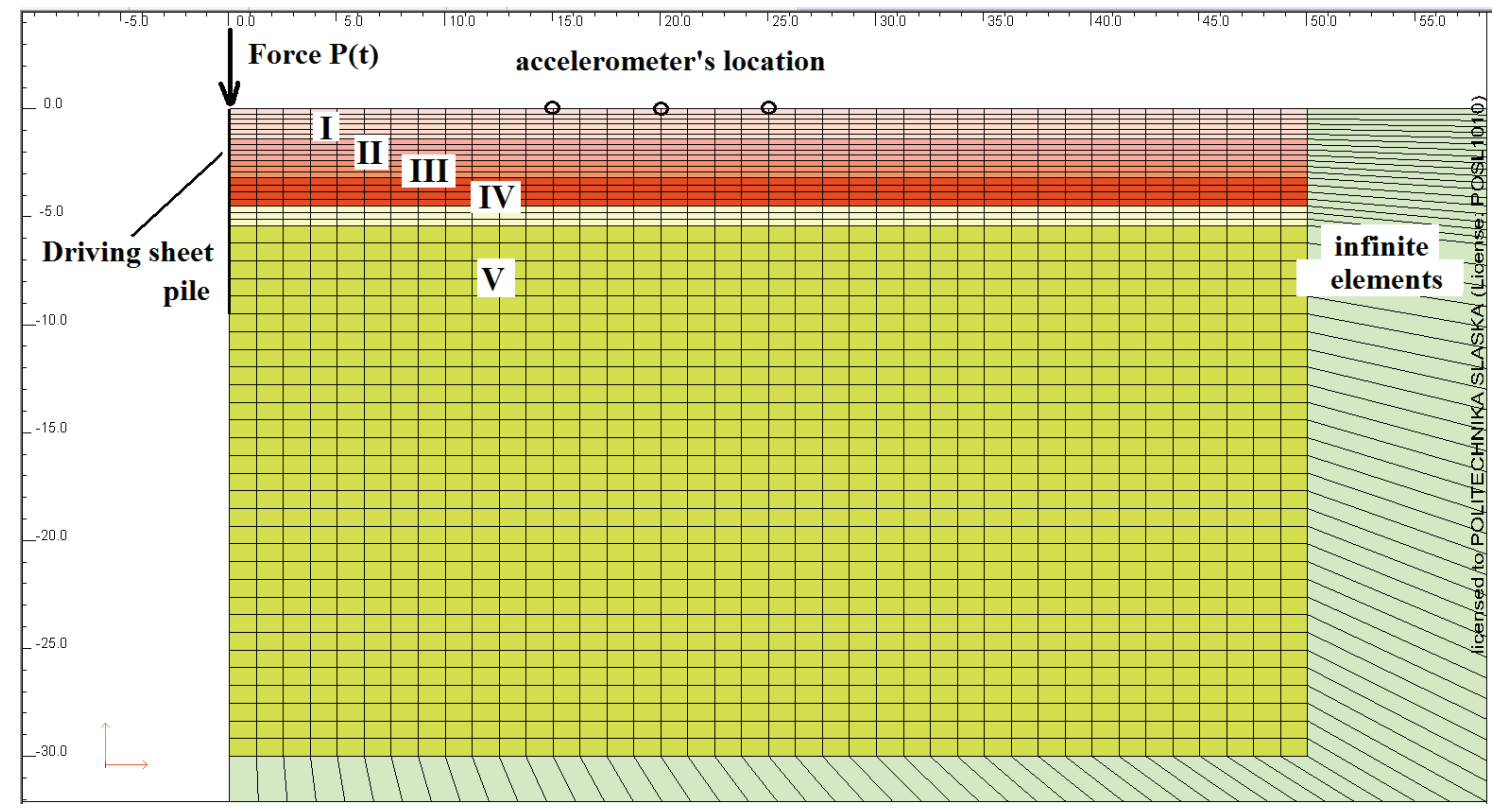

Fig. 10. Formulation of the initial boundary problem 
others the one from Fig. 7b (layer I - upper line, layer II - lower one). It should be emphasised here that because during implementation of majority of Polish investments advanced subsoil studies are not carried out (only simple subsoil recognition is made) the estimation of complex models parameter values is extremely difficult. The other values of RU+MCC model parameters (Uliniarz [12]) were assumed identical for all layers of subsoil analysed:

$$
\begin{gathered}
M=1.0, k=1.0, \quad v=0.3, \lambda=0.05, \kappa=0.01, \\
p_{c 0}=1000 \mathrm{kPa}, n=1, t_{1}=3, t_{2}=7 .
\end{gathered}
$$

Table 1

Parameter $G^{*}$ values taken for calculations

\begin{tabular}{|c|c|c|c|c|c|}
\hline $\begin{array}{c}\text { No } \\
\text { of material } \\
\text { zone }\end{array}$ & $\begin{array}{c}\text { I: clSa, } \\
I_{L}=0.35\end{array}$ & $\begin{array}{c}\text { II: siCL, } \\
I_{L}=0.35\end{array}$ & $\begin{array}{c}\text { III: Cl, } \\
I_{L}=0.12\end{array}$ & $\begin{array}{c}\text { IV: Cl, } \\
I_{L}=0.40\end{array}$ & $\begin{array}{c}\text { V: Cl, } \\
I_{L}=0.05\end{array}$ \\
\hline Value of $G^{*}$ & 5800 & 1160 & 1040 & 490 & 1625 \\
\hline
\end{tabular}

A simplification was made in the analysis, consisting in assuming symmetry of the problem (only its half was considered) and a plane strain state. The latter assumption is justified on an additional assumption that a thin fragment of subsoil is analysed (strip) together with a short element of currently being driven sheet pile - a cross-section to the sheet pile being introduced. Deformations of the soil environment were described by continual elements - four-hub tetragons. The driven sheet pile was modelled by beam elements, while the contact between the sheet pile and the surrounding soil was simulated by so-called interface element available in the Z_Soil software. Depending on the current wall length a number of problems were resolved, each of which corresponds to a different length of the wall existing in the subsoil at the moment. Proper defining of boundary conditions is also an important element of the analysis. Application of classical non-slidable supports on the edges of nu- merical model gives the effect of wave reflection, which entirely disturbs obtained results and may be the reason for gross errors. Therefore, infinite elements were used (Fig. 10), which task is to absorb the energy of propagating wave at the ends of analysed area (cf. Truty [11]). Typical conditions were applied on the remaining model edges - non-slidable support in direction perpendicular to the model symmetry axis and on the top edge - a zero normal stress.

A fully implicit Newmark scheme was used for equations of motion integration and the incremental step was $0.001 \mathrm{~s}$. The subsoil response to applied force was analysed and the results discussed comprise values of acceleration amplitudes at points on the ground surface at the following distances from the sheet piles vibratory driving: $15 \mathrm{~m}, 20 \mathrm{~m}$, and $25 \mathrm{~m}$, which closely corresponds to the location of measurement points described in Section 2. Results obtained from numerical analyses in Fig. 11 have been compared with results of field tests described in Section 2 for sheet pile III. Values on the vertical axis mean the depth, at which the sheet pile has been driven into the subsoil at the moment of measurement making or obtaining analysis result.

Based on the obtained measurement results it is possible to reckon that a relatively good agreement was obtained between simulation results and field tests. It should be emphasised that the value of acceleration registered at a specific point is the most significant information based on which the reach of impact and arduousness of given works type on the neighbourhood are evaluated. It could be observed that most accelerations analyzed show the decreasing tendency with depth. For limited depths (up to $3.5 \mathrm{~m}$ below the ground level) and for accelerations measured at a distance of $20 \mathrm{~m}$ from the driven sheet even increase of them was noticed, which may be connected with lack of precise recognition of subsoil or it may be influence of existing sheets, driven into the ground before. These effects are not taken into ac-
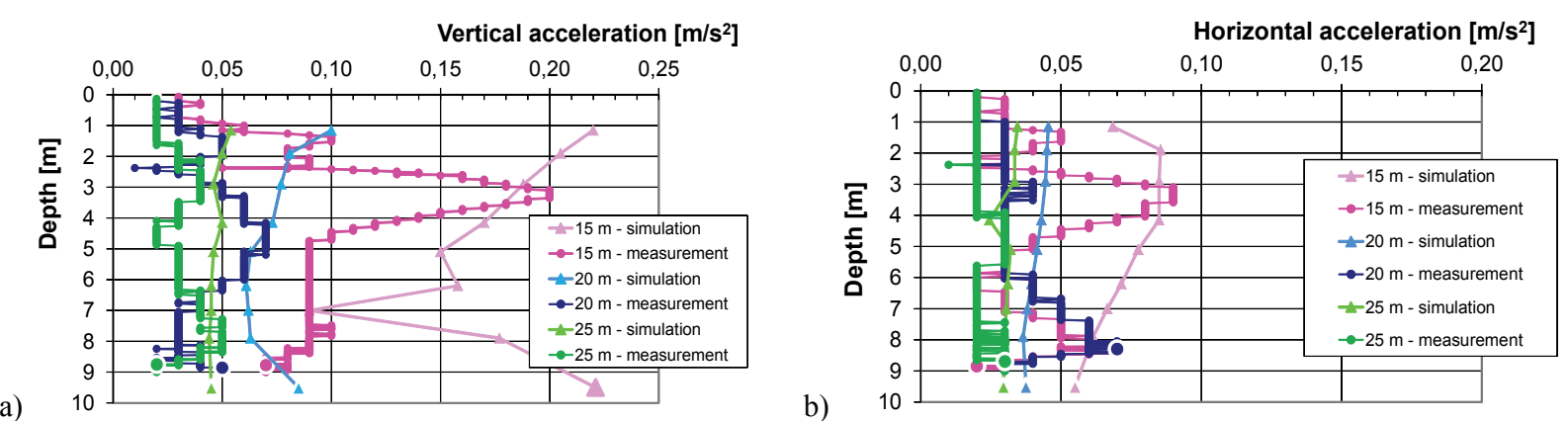

Fig. 11. Comparison of analyses results with field tests results: (a) vertical accelerations amplitudes, (b) horizontal acceleration amplitudes 
count in the analyses performed. For real building structures accelerations of $0.02 \mathrm{~m} / \mathrm{s}^{2}$ may be already perceptible, depending on the frequency of vibrations accompanying the wave propagation. In the case presented the obtained (both from measurements and from numerical calculations) interaction values substantially exceed this value, therefore the application of this technology of sheet piles forming in immediate vicinity of buildings would create hazard to their structure. Moreover, a general trend for decreasing influences with the depth of sheet pile driving (vibration effects are perceived primarily at the beginning) is visible in the graphs, which also proves the truth of obtained results. In general, the problem presented is very difficult to simulate because of the large quantity of variable factors affecting the results.

\section{CONCLUSIONS}

The solution presented in the paper becomes part of complex analysis of soil environment behaviour subject to dynamic loads. The soil environment response to the generated forces was analysed using an example of sheet pile vibratory driving into the subsoil. Proper recognition of soil properties in terms of deformations, which occur during the observed phenomena, is necessary for realistic modelling of such difficult issues.

Methodology of carrying out laboratory tests, enabling determination of soil behaviour characteristics in the area of small deformations was presented during the title problem resolution. The tests performed enabled calibration of the assumed constitutive model, which was aimed at realistic description of soil behaviour as a response to applied impact. This model was used in dynamic analyses of soil environment behaviour during sheet pile vibratory driving into the subsoil.

Comparison of results obtained from numerical analyses with results of site measurements has shown that the applied procedure gives satisfactory results. Conclusions from analyses may be used for accurate evaluation of the environmental impact reach, which is significant in practical issues, when designing the technology of work execution. Moreover, the procedure presented enables realistic prediction of impact effects.

Further tests are planned for the future, comprising first of all a realistic description of damping mechanism and also of methods for effective calibration of complex constitutive model based on laboratory and field tests. The optimum solution would consist of parameter values estimation based on penetration tests using a static penetrometer and backward analysis, based on monitoring of technological shock impact on the surroundings within investment implementation.

\section{REFERENCES}

[1] Ciesielski R., Kwiecień A., StypuŁa K., Vibrations Propagation in Subsoil Superficial Layers, Monograph, 263, Krakow University of Technology Publishers, 1999, (in Polish).

[2] GRYCZMAŃSKi M., UliniaRZ R., A simple critical state model with small strain nonlinearity for overconsolidated soils, Foundations of Civil and Environmental Engineering, 2008, $12,49-60$.

[3] Jardine R.J., Potts D.M., Fourie A.B., Burland J.B., Studies of the influence of nonlinear stress-strain characteristics in soil structure interaction, Geotechnique, 1986, 36, 377-396.

[4] JarominiaK A., Light Earth Retaining Structures, Wydawnictwo Komunikacji i Łączności, Warszawa 2000, (in Polish).

[5] JARON A., The measurement of surface vibrations in the ground caused by sheet piles vibratory driving in cohesive soils, Inżynieria Morska i Geotechnika, 2012, 4, 339-343, (in Polish).

[6] JASTRZĘBSKA M., Calibration and verification of a single surface elasto-plasic model for soil with strongly nonlinear anisotropic hardening law, Ph.D. Thesis, Silesian University of Technology, 2002, (in Polish).

[7] JASTRZĘBSKA M., Investigations of the behaviour of cohesive soils subject to cyclic loads in the area of small deformations, D.Sc. Monograph, 251, Silesian University of Technology Publishers, Gliwice 2010, (in Polish).

[8] Legrand C., VAn Rompaey D., Menten J., A comparison of different sheet-pile installation methods, Fifth International Conference \& Exhibition on Piling and Deep Foundations, Bruges, Belgium, (DFI), 1994, 762, 36.

[9] LipińSKi M., GRYCZMAŃSKi M., JASTRZęBSKA M., Łupieżowiec M., ZIENkIEWICZ B., MARKowsKa K., Wudzka A., Wdowska M., Non-linearity of Stress-Strain Characteristics in Soil Pre-failure States - Experimental Grounds of Theoretical Description, MS\&I Research Project No. 5 T07E 038 24, SGGW Warszawa, Silesian University of Technology Gliwice, IPPT PAN Warszawa 2006, (in Polish).

[10] ŁuPIEŻOWIEC M., Model of the propagation vibrations caused by dynamic consolidation by FEM analysis, Inżynieria Morska i Geotechnika, 2012, 4, 352-357, (in Polish).

[11] TRUTY A., Application of domain reduction method in dynamic problems of soil-structure interaction, Technical Transactions, Environmental Engineering, 2010, 16, 101115, (in Polish).

[12] ULINIARZ R., Critical state model for overconsolidated soil and its application in geotechnics, $\mathrm{PhD}$ thesis, Silesian University of Technology, Gliwice 2012, (in Polish).

[13] VIKING K., Vibro-driveability - a field study of vibratory driven sheet piles in non-cohesive soils, $\mathrm{PhD}$ Thesis, Department of Civil and Architectural Engineering Royal Institute of Technology (KTH), Stockholm, Sweden, 2002. 
[14] ZEILINGER H., The Vibro-jetting driving method, 18 Int. Foundation Congress and Equipment Expo, Contemporary Topics in Deep Foundations, Publications (GSP), ASCE, 2009, 311-319,

[15] Zimmermann Th., Truty A., Urbański A., Podleś K., Z_Soil.PC $20113 D$ user manual, Theory, Tutorials and Benchmarks, Data Preparation, Elmepress International \& Zace Services, Ltd., Switzerland, 2011.

[16] Documentation (2011), Geological-engineering documentation for the project of residental building with services and built-in two-storeyed garage on the site no 57/280, district 47 Podgorze by W. Sławek street in Cracow, Company: Przedsiębiorstwo usługowe "Geo San" mgr inż. Zdzisław Jarocki, (in Polish),

[18] Documentation (2012), Geotechnical documentation for the area under the residetal building on the site no $57 / 280$, distr. 47, after a damage of the water pipe in April 2012 by W. Sławek street in Cracow (Podgorze district), Company: Usługi geologiczne dr Jerzy Brzozowski, (in Polish). 